\title{
The influence of classical interpretation on the law of guarantees in the United Arab Emirates.
}

\begin{abstract}
During the past four decades, the world has awakened with the reassertion of Islamic law in the Muslim world. At this point, the reassertion also means the embedment of classical interpretations in modern law as they are regarded as part of Islamic law. The question that arises is how far these classical interpretations bind modern legislators and to what extent, if any, classical interpretations influence the development of modern legal principles. This article seeks to clarify these issues through the examination of the law of guarantees in the United Arab Emirates. Both classical and modern legal sources of the United Arab Emirates have been examined for the above purpose. The study demonstrates that classical interpretation has a profound influence in the development of the law of guarantees in the United Arab Emirates.
\end{abstract}

Keyword: Guarantees; Classical interpretation; UAE Civil Code 1985; Islamic law. 